\title{
Financial innovation and arbitrage in the Spanish bond market
}

\author{
Alejandro Balbás*and Susana LóPeZ ${ }^{\dagger \ddagger}$ \\ Working Paper 01-01 \\ Bussines Economics Series \\ January 2001 \\ Departamento de Economía de la Empresa
}

\begin{abstract}
This paper empirically tests the level of sequential arbitrage in the Spanish bond market. The test is implemented by drawing on default free and option free pure discount and coupon bonds issued by the Spanish government. This fact seems to be a clear distinction between this paper and the related empirical literature since there are no risky bonds or derivative securities involved in our analysis. As a consequence, the sequential arbitrage absence is just equivalent to the existence of a term structure of interest rates matching the whole set of bond prices as provided by The Bank of Spain. Thus, the main conclusions seem to be robust because they only depend on very general and simple hypotheses and, particularly, no dynamic assumptions are required. The results of the empirical analysis may be useful to traders and researchers since it seems to reveal the existence of sequential arbitrage. Furthermore, the number of arbitrage opportunities significantly increased in 1998, when important innovations were implemented and, amongst other new possibilities, agents began trading each whole bond and its coupons (strips) separately. The inexperience associated with financial innovations may lead to inefficiencies in the market.
\end{abstract}

\section{INTRODUCTION}

The absence of arbitrage opportunities, or sequential arbitrage opportunities in the case of bond markets, is a basic assumption very common in financial literature. The existence of arbitrage is hardly compatible with any kind of equilibrium and, therefore, no arbitrage conditions are almost always assumed in every classical theoretical approach concerning asset pricing or asset allocation.

\footnotetext{
*Universidad Carlos III. Departamento de Economía de la Empresa. C/ Madrid 126. 28903 Getafe (Madrid Spain). balbas@emp.uc3m.es

${ }^{\dagger}$ Universidad Carlos III. Departamento de Economía de la Empresa. C/ Madrid 126. 28903 Getafe (Madrid Spain). slopez@est-econ.uc3m.es

$\ddagger$ Partially funded by "Comunidad Autónoma de Madrid" (ref: CAM 07T/0027/2000) and Spanish Ministry of Science and Technology (ref: BEC2000-1388-C04-03)
} 
However the empirical evidence seems to reveal that the arbitrage may occur in practice (see for instance Lee and Nayar (1993), Chen and Knez (1995), Kamara and Miller (1995), Kempf and Korn (1998), Balbás et al. (2000) and Grinblatt and Longstaff (2000)) and this fact has motivated several authors to introduce new viewpoints. A first line of research focuses on market imperfections because they can make the arbitrage be apparent but not real. So, Jouini and Kallal (1995) present a general treatment of transaction costs and their influence on classic theoretical results concerning arbitrage free models, Schleifer and Vishny (1997) illustrate many real problems when dealing with arbitrage strategies and Liu and Longstaff (2000) prove that, under adequate assumptions, margins can make it convenient to abandon available arbitrage strategies in order to optimize the portfolio choice.

Another line of research is related to the arbitrage measurement (see for instance Holden (1995), Chen and Knez (1995), Kempf and Korn (1998), Balbás and Muñoz (1998) or Balbás and López (2000)). In this case authors try to provide us with appropriate measures containing numerical information about the size or degree of arbitrage. If this information incorporates monetary gains associated with the available arbitrage then the effect of some imperfections can be discounted and the theory applies for imperfect markets too. In some sense both approaches are complementary.

The present article is based on the second approach since it uses some measures introduced in Balbás and Muñoz (1998) and Balbás and López (2000) and empirically tests the level of sequential arbitrage in the Spanish bond market.

The existence of state price densities in a general market, or the existence of a term structure of interest rates (henceforth $T S I R$ ) in a bond market, is the necessary and sufficient condition to guarantee that the market is arbitrage free, or sequential arbitrage free if dealing with bond markets (see for instance Hansen and Jagannathan (1997) or Ait-Sahalia and Lo (1998) for general markets and Jaschke (1998) for bond markets). This property plays a crucial role when constructing most of the above mentioned arbitrage measures and, specially, those applying in this paper. So, Balbás and López (2000) focus on an arbitrary bond market and introduces several optimization problems minimizing the real price modifications (in percentage) that lead to the existence of a TSIR matching the whole set of bond prices. The minimum values are the sequential arbitrage measures. Dual optimization problems give optimal sequential arbitrage strategies and show that these measures may be also interpreted in terms of relative sequential arbitrage earnings. Consequently, when we test the measure values in real bond markets we obtain both optimal relative sequential arbitrage strategies and profits and minimal relative modifications of prices leading to sequential arbitrage free models.

When empirical papers analyze the existence of arbitrage they usually focus on well-known strategies and formulas. For instance, Sternberg (1994) or Kamara and Miller (1995) test the existence of violations of put-call parity, Harris et al. (1995) test 
the price of specific assets or portfolios in different markets, Protopapadakis and Stoll (1983) test the usual relationship between spot and future prices and Lee and Nayar (1993) analyze some relationships between European options and future contracts.

Arbitrage measures also allow us to consider all the available securities and portfolios when testing the market. So, Balbás et al. (2000) draw on the Balbás and Muñoz (1998) measure and empirically analyze the level of cross-market arbitrage between the Spanish stock market and its derivative market without previously specifying the exact nature of the arbitrage strategy to be used. Unlike previous studies, these authors globally analyze the market in order to consider all the available arbitrage strategies and choose the optimal one.

Despite the vast empirical literature devoted to analyze the existence of arbitrage in stock and derivative markets, and the vast number of empirical papers focusing on bond prices and the TSIR, one misses further empirical evidence concerning the existence of sequential arbitrage in bond markets. Although bond markets and the $T S I R$ deserved and will go on deserving a major attention, see for instance Elton et al. (1990), Bowden (1997), Jaschke (1998), Aniz and Prisman (2000) or Balbás et al. (2001) for recent results, there is a clear lack of empirical analyses related to the existence and computation of sequential arbitrage strategies in practice. This fact is probably provoked because there are no well-known arbitrage strategies and formulas when dealing with fixed income securities, unless their derivatives are also involved. In this sense, the global approach of Balbás et al. (2000) may be quite suitable when testing bond markets.

The present paper only draws on default free and option free bonds issued by the Spanish government and tests the degree of sequential arbitrage within the time interval 1994-1998. This fact seems to be a clear distinction between this paper and the related empirical literature since there are no risky bonds or derivative securities involved in our analysis. As a consequence, the main conclusions seem to be robust because they only depend on very general and simple hypotheses and, particularly, no dynamic assumptions are required. We follow the methodology of Balbás et al. (2000) but we use some Balbás and López's measures (hereafter denoted by $\tilde{£}_{*}$ and $£_{* *}$ ) instead of the Balbás and Muñoz's one. $\tilde{£}_{*}$ and $£_{* *}$ better capture some properties of sequential arbitrage strategies and bond markets.

The results of our analysis may be useful to traders, managers and researchers. Our test reports practical tools and strategies, the level of sequential arbitrage and it also yields further evidence about market efficiency outside the $U S A$.

We concentrate on the Spanish market "Mercado de Deuda Anotada" and the database provided The Bank of Spain, which contains prices, liquidity and other significant information. It is important to point out that Spanish financial markets present appropriate characteristics such as their computerized trading system, their phenomenal recent growth and the positive results that have been obtained when 
other tests of efficiency have been implemented. For instance, Lee and Mathur (1999) show that the random walk hypothesis cannot be rejected in the Spanish futures markets, while the fulfillment of this hypothesis is not so clear when dealing with another European futures markets.

Despite the comment above the results of our analysis are in the line of those reported by Balbás et al. (2000), i.e., the existence of sequential arbitrage cannot be rejected. Hence, global tests based on the theoretical foundations of asset pricing may indicate inefficiency despite previous tests of standard and well-known strategies, simple technical trading rules, or related techniques may have reflected just the opposite.

Besides, it must be also pointed out that the number of sequential arbitrage opportunities and the value of the sequential arbitrage measures significantly increased in 1998, when important innovations were implemented in the market and, amongst other new possibilities, agents began trading each whole bond and its coupons (strips) separately. Consequently, it seems that the inexperience associated with financial innovations may lead to inefficiencies in the market.

Finally, as pointed out in Balbás et al. (2000), the arbitrage measurement may also be helpful when analyzing arbitrage-free markets since this measurement may yield new practical strategies to invest and price new securities. Following a similar procedure, our analysis may be also useful on those dates reflecting the absence of sequential arbitrage since it may apply when pricing new bonds or diversifying among available bonds.

The article is organized as follows: Section 2 summarizes those theoretical results that were applied when implementing the empirical test. Section 3 analyzes and describes the market, the data, the empirical results and presents some concrete sequential arbitrage strategies that were available in the market. Section 4 summarizes and concludes the article.

\section{Preliminaries, notations And theoretical BaCKGround}

This section is devoted to present a brief synopsis of those theoretical results that were applied when testing the degree of arbitrage in the Spanish bond market. Proofs are omitted since almost all of them may be found in Balbás and López (2000) or another appropriate reference that will be provided.

Consider $n$ arbitrary bonds $B_{j}, j=1,2, \ldots, n$, available in the market, and denote by $p=\left(p_{1}, p_{2}, \ldots, p_{n}\right), p_{j}>0, j=1,2, \ldots, n$, the vector whose components are their current prices. Suppose that $T=\left\{t_{1}, t_{2}, \ldots, t_{m}\right\}$ represents the set of future dates in which bondholders will receive the corresponding payoff and denote by $a_{i j} \geq 0$ the amount of money paid by $B_{j}$ at $t_{i}, i=1,2, \ldots, m, j=1,2, \ldots, n$. In order to ensure that all the statements of this section hold we have to impose the following weak 
inequality whose economic interpretation is obvious

$$
\sum_{i=1}^{m} a_{i j}>p_{j}
$$

for every $j=1,2, \ldots, n$. Consider finally that $A$ represents the $m \times n$ matrix whose rows are $A_{i}=\left(a_{i, 1}, a_{i, 2}, \ldots, a_{i, n}\right), i=1,2, \ldots, m$, and $\tilde{A}=\left(\begin{array}{c}A_{0} \\ A\end{array}\right)$ represents the $(m+1) \times n$ matrix obtained by adding $A$ plus a first row equal to $A_{0}=-p$. If $X=\left(x_{1}, x_{2}, \ldots, x_{n}\right)$ represents the portfolio composed of $x_{j}$ units of $B_{j}, j=1,2, \ldots, n$, then $p X^{T}$ equals the current price of $X, A X^{T}$ equals its future payoffs and $\tilde{A} X^{T}$ equals the whole set of cash flows of $X .{ }^{1}$ The following matrices, whose dimensions are $m \times m$ and $m \times(m+1)$ respectively, will also play an important role in the analysis

$$
I_{m}^{*}=\left(\begin{array}{c}
1,0,0, \ldots, 0 \\
1,1,0, \ldots, 0 \\
\ldots \ldots \\
1,1,1, \ldots, 1
\end{array}\right), \quad I^{* *}=\left(\begin{array}{c}
1,1,0, \ldots, 0 \\
1,1,1, \ldots, 0 \\
\ldots \ldots . . \\
1,1,1, \ldots, 1
\end{array}\right)
$$

and $I_{m+1}^{*}$ will be similar to $I_{m}^{*}$ but with $m+1$ rows and columns.

We follow the previous literature in order to introduce the concept of sequential arbitrage.

Definition 1. $X$ is said to be a sequential arbitrage portfolio if $I_{m+1}^{*} \tilde{A} X^{T} \neq 0$ and $I_{m+1}^{*} \tilde{A} X^{T} \geq 0 .^{2}$

It is known that the sequential arbitrage absence may be characterized by the existence of decreasing and positive discount factors (or a TSIR). The statement below clarifies this idea.

Theorem 2. The model is sequential arbitrage free if and only if there exists $\mu=$ $\left(\mu_{1}, \mu_{2}, \ldots \mu_{m}\right)$ such that $1>\mu_{1}>\mu_{2}>\ldots>\mu_{m}>0$ and $\mu A=p$.

In order to measure the level of sequential arbitrage Balbás and López (2000) introduce some extensions of Definition 1. The authors adopt the concept "arbitrage of the second type" in the line of Ingersoll (1989), Chapter 2. Mainly, this sort of sequential arbitrage implies a positive income at the current date.

\footnotetext{
${ }^{1}$ As usual, given an arbitrary matrix $M$, the transpose of $M$ will be denoted by $M^{T}$.

${ }^{2}$ As usual, given an arbitrary matrix $M$, the inequality $M \geq 0$ means that $M$ does not contain any negative element. Similar notations will appear in similar cases. Notice that, according to Definition 1, if a sequential arbitrage portfolio implied any negative cash flow then it should be overcome by the amount of money previously received.
} 
Definition 3. $X$ is said to be a sequential arbitrage portfolio of the second type if $p X^{T}<0$ and $I^{* *} \tilde{A} X^{T} \geq 0$.

$X$ is said to be a strong sequential arbitrage portfolio if $p X^{T}<0$ and $I_{m}^{*} A X^{T} \geq 0$.

Obviously, strong sequential arbitrage portfolios are also sequential arbitrage portfolios of the second type, but the converse does not necessarily hold. The absence of strong and second type sequential arbitrage is characterized by the following result (see Balbás and López (2000) for a complete proof)

Theorem 4. The model is second type (respectively, strong) sequential arbitrage free if and only if there exists $\mu=\left(\mu_{1}, \mu_{2}, \ldots \mu_{m}\right)$ such that $1>\mu_{1} \geq \mu_{2} \geq \ldots \geq \mu_{m} \geq 0$ (respectively, $\mu_{1} \geq \mu_{2} \geq \ldots \geq \mu_{m} \geq 0$ ) and $\mu A=p$.

Balbás and López (2000) establish the existence of solution for the minimax problem

$$
\operatorname{Min}\left[\operatorname{Max}\left\{\frac{p_{j}-q_{j}}{p_{j}} ; j=1,2, \ldots, n\right\} ; q=\mu A, q \leq p, \mu_{1} \geq \mu_{2} \geq \ldots \geq \mu_{m} \geq 0\right]
$$

$q=\left(q_{1}, q_{2}, \ldots, q_{n}\right)$ and $\mu=\left(\mu_{1}, \mu_{2}, \ldots \mu_{m}\right)$ being the decision variables. Denoting by $p_{* *}$ and $\mu_{* *}$ the solution of (1) and by

$$
£_{* *}=\operatorname{Max}\left\{\frac{p_{j}-p_{* * j}}{p_{j}} ; j=1,2, \ldots, n\right\}
$$

the minimax value, $£_{* *}$ may be understood as a measure of the degree of strong sequential arbitrage since, according to Theorem $4, £_{* *}$ is the minimum fall (in percentage) of real prices that leads to a strong sequential arbitrage free model. It may be proved that $0 \leq £_{* *}<1, £_{* *}=0$ if and only if the model is strong sequential arbitrage free, and $0<p_{* * j} \leq p_{j}, j=1,2, \ldots, n$.

The measure $£_{* *}$ may also be interpreted in terms of arbitrage profits. In fact, assume that $X$ is a strong sequential arbitrage portfolio whose short position $X^{-}$has a price equal to one dollar. ${ }^{3}$ It may be proved that the price of $X^{+}$verifies $p X^{-T}-$ $p X^{+T} \leq £_{* *}$ and, moreover, there exists a strong sequential arbitrage portfolio $X_{* *}$ such that $p X_{* *}^{-T}=1$ and $p X_{* *}^{-T}-p X_{* *}^{+T}=£_{* *}$. Thus, $X_{* *}$ maximizes the profit generated by a strong sequential arbitrage portfolio whose short position has a value equal to one dollar and, moreover, the optimal profit equals $£_{* *}$ dollars.

$X_{* *}$ also maximizes another interesting objectives that may be interpreted as relative arbitrage earnings. For instance it maximizes the ratio between sequential

\footnotetext{
${ }^{3}$ As usual, $\alpha^{+}=\operatorname{Sup}\{\alpha, 0\}, \alpha^{-}=\operatorname{Sup}\{0,-\alpha\}$ and $\alpha=\alpha^{+}-\alpha^{-}$for every $\alpha \in \mathbb{R}$. Similar notations are also used for vectors and matrices.
} 
arbitrage profits and the price of the sold bonds, the ratio between sequential arbitrage profits and the price of the purchased bonds and the ratio between sequential arbitrage profits and the total traded value (i.e. $\frac{p X_{* *}^{-T}-p X_{* *}^{+T}}{p X_{* *}^{-T}} \geq \frac{p X^{-T}-p X^{+T}}{p X^{-T}}$, $\frac{p X_{* *}^{-T}-p X_{* *}^{+T}}{p X_{* *}^{+T}} \geq \frac{p X^{-T}-p X^{+T}}{p X^{+T}}$ and $\frac{p X_{* *}^{-T}-p X_{* *}^{+T}}{p X_{* *}^{-T}+p X_{* *}^{+T}} \geq \frac{p X^{-T}-p X^{+T}}{p X^{-T}+p X^{+T}}$ hold for every strong sequential arbitrage portfolio $X)$. Furthermore, the first ratio optimal value equals $£_{* *}$ (see Balbás and Muñoz (1998) and Balbás and López (2000)).

In order to simplify the notation we will define $h_{* *}=X_{* *}^{-}$and $k_{* *}=X_{* *}^{+}$. Hence $h_{* *}$ and $k_{* *}$ are portfolios without short positions such that $k_{* *}$ sequentially dominates $h_{* *}$, the price of $k_{* *}$ is $1-£_{* *}$, the price of $h_{* *}$ is 1 and $k_{* *}-h_{* *}$ is the optimal strong sequential arbitrage portfolio. The arbitrage arises because those bonds included in $k_{* *}$ are cheap since they verify

$$
p_{* * j}=p_{j}
$$

while the bonds composing $h_{* *}$ are expensive since

$$
p_{* * j}=p_{j}\left(1-£_{* *}\right)
$$

According to the minimax condition, the minimum relative fall that prevents the arbitrage makes the price of those bonds included in $h_{* *}$ decrease in the percentage indicated by $£_{* *}$. If $B_{j}$ is neither included in $k_{* *}$ nor included in $h_{* *}$ then $p_{j}\left(1-£_{* *}\right) \leq$ $p_{* * j} \leq p_{j}$.

Things are more complex when dealing with second type sequential arbitrage portfolios because in this case the minimax condition does not necessarily hold. However, as long as the model is not second type sequential arbitrage free, we can still prove the existence of a second type sequential arbitrage portfolio $X_{*}$ that maximizes the ratio between the arbitrage income and the value of the short position, the long position or the total traded value. $£_{*}$ will denote the first ratio optimal value. The portfolio $X_{*}$ achieves the form $X_{*}=k_{*}-h_{*}, k_{*}$ and $h_{*}$ being its long and short position respectively. $h_{*}$ may be normalized so that its price can equal one in which case the price of $k_{*}$ takes the form $1-\tilde{£}_{*}, \tilde{£}_{*}$ verifying the constraints

$$
0 \leq £_{* *} \leq \tilde{£}_{*}<£_{*}<1
$$

There exists a family of prices $p_{*}=\left(p_{* 1}, p_{* 2}, \ldots, p_{* n}\right)$ providing a second type sequential arbitrage free model and such that

$$
p_{* j}=p_{j}
$$

if $B_{j}$ belongs to $k_{*}$,

$$
p_{* j}=p_{j}\left(1-\tilde{£}_{*}\right)
$$


if $B_{j}$ belongs to $k_{*}$ and $p_{j}\left(1-\tilde{£}_{*}\right) \leq p_{* j} \leq p_{j}$ otherwise. Whence, $\tilde{£}_{*}$ may also be understood as a measure of the level of second type sequential arbitrage since it provides us with the fall (in percentage) of prices that makes the income given by

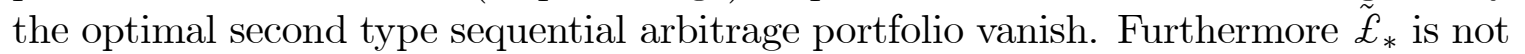
only a "pricing error" committed by the market since the inequality $\tilde{\mathscr{E}}_{*}<£_{*}$ (see (4)) shows that $\tilde{£}_{*}$ is a lower bound for the optimal relative second type sequential arbitrage income.

\section{Market, DATA, EMPiRICAL Results AND EXAMPles}

Our test focused on the so called "Mercado de Deuda Anotada" (MDA in what follows), the most liquid market when trading default free and option free bonds issued by the Spanish government. Some bonds with risk premium or embedded option are also available in $M D A$ but we did not consider them in order to avoid as much noise as possible. $M D A$ is organized by The Bank of Spain and this institution elaborates a complete database containing each type of bond with its corresponding characteristics, daily prices, volume and other significant information. Our test was implemented by employing this database.

We have focused on Years 1994 and 1998 and day by day $\tilde{£}_{*}$ and $£_{* *}$ have been computed, along with $X_{* *}, h_{* *}, k_{* *}, X_{*}, h_{*}$ and $k_{*}$. There is not any special reason to choose 1994 . We just tried to test an arbitrary year and made a random decision. On the contrary, 1998 reflects several financial innovations that can provoke unusual behaviors of the market. For instance, in 1998 agents began trading each whole bond and its strips separately.

In order to confirm that 1994 is an arbitrary year we selected a brief sample of days within the time interval 1995 - 1997 and the results were analogous to those obtained for 1994. Besides, if we eliminate strips from the database of 1998 then we obtain similar results once more.

Tables 1 and 2 summarize the results. A first remark should point out that many values of $£_{* *}$ and $\tilde{£}_{*}$ are almost equal. Although from theoretical viewpoints there are some differences between the concepts of strong sequential arbitrage and second type sequential arbitrage, the empirical test seems to reveal that both approaches may lead to analogous results in practice. Tables 1 and 2 show that the levels of both types of arbitrage are closely related.

Tables 1 and 2 also illustrate that the sequential arbitrage existence cannot be globally rejected. Since the test only deals with default free and option free bonds it is clear that the lack of an homogeneous fiscal treatment for all the available bonds or the lack of intradaily perfectly synchronized data are the unique reasons that might justify the high values attained by $£_{* *}$ and $\tilde{£}_{*}$.

With respect to the second caveat, it was not possible for us to obtain intradaily perfectly synchronized prices. Nevertheless, it is important to recall that $£_{* *}$ repre- 
sents the minimum variation of prices that prevents the strong sequential arbitrage (see Theorem 4 and $(1)$ ) and, according to the empirical evidence concerning the volatility of bond prices and interest rates, many values attained by $£_{* *}$ are far larger than those that could be expected. Moreover, if the lack of synchronization made it difficult to implement sequential arbitrage it would be still obvious that some investors obtained prices and returns significantly different to those provided by a sequential arbitrage free market and significantly better or worse than those generated by any $T S I R$. So, investors who bought bonds included in $k_{*}$ or $k_{* *}$ (respectively, who sold bonds included in $h_{*}$ or $h_{* *}$ ) obtained far better returns than those achieved by investors buying (selling) bonds of $h_{*}$ or $h_{* *}\left(k_{*}\right.$ or $\left.k_{* *}\right)$. This assertion is also supported by Expressions (2), (3), (5) and (6) and by the interpretation of the sequential arbitrage measures in terms of relative arbitrage gains.

Regarding the fiscal treatment, and bearing in mind the interest rate levels in the tested years, even under the most pessimistic scenario it is rather difficult to accept that tax effects may imply a value of $£_{* *}$ greater than 25 basic points in 1994 or 15 basic points in 1998. ${ }^{4}$ Furthermore, the most favorable fiscal treatment corresponds to strips and the so called "Letras del Tesoro" (zero coupon bonds whose maturity is shorter than one year and half) but it will be shown at the end of this section that $X_{* *}$ some days incorporates some "Letras del Tesoro" (from now on LT) or strips in long position, or coupon bonds in short position.

There are obvious differences between 1994 and 1998. 1998 was characterized by several innovations in $M D A$, strips being the most important (but not the unique) one. The level of arbitrage in 1998 seems to be too high, which suggests that the inexperience associated with financial innovations may lead to inefficiencies in the market.

It is worthwhile to remark that Spanish financial markets have shown a high level of efficiency when several classical tests have been implemented. For example, Lee

\footnotetext{
${ }^{4}$ For instance, if we focus on 1998, then we can assume an interest rate level whose average value is lower than $5 \%$. Suppose that an agent implements the arbitrage portfolio $X_{* *}=k_{* *}-h_{* *}$. Since the arbitrage profit equals $£_{* *}$, capital losses caused by the tax effect should be lower than $£_{* *}$. Thus, the net present value of those taxes that must be anticipated when holding $k_{* *}$ should be lower than $£_{* *}$. According to the Spanish law the percentage of anticipated taxes is not homogeneous and depends on the agent and on her/his portfolio. The most negative situation arises if each coupon $c$ of $k_{* *}$ forces the bondholder to anticipate the tax $0.25 c$ for one year. According to our empirical results we can assume that $k_{* *}$ matures in three years on average and pays an annual coupon $c=0.05\left(1-£_{* *}\right)$. Hence, we have that

$$
£_{* *} \geq 0.05 \times 0.25 \times\left(1-£_{* *}\right)\left[\sum_{i=1}^{3} \frac{1}{1.05^{i}}-\frac{1}{1.05^{i+1}}\right]
$$

is a sufficient (but not necessary) condition to guarantee after-tax arbitrage profits. Now, simple manipulations lead to $£_{* *} \geq 0.0015$.
} 
and Mathur (1999) show that the random walk hypothesis cannot be rejected in the Spanish futures markets, while the fulfillment of this hypothesis is not so clear when dealing with another European futures markets. However, our results are in the line of those obtained in Balbás et al. (2000), where it is shown that some arbitrage strategies were available in the derivative market whose underlying security consists of the Spanish index $I B E X-35$. As already said, our test and the test of Balbás et al. (2000) analyze the market by applying several foundations of asset pricing theory, and without previously specifying the exact nature of the arbitrage strategy to be used. This could be a crucial key to understand these results.

The remainder of this section is devoted to present some concrete strong sequential arbitrage portfolios occurred in 1998. The purpose of these concrete examples is just to illustrate how sequential arbitrage measures work in practice.

We will present strategies but we will not illustrate that they are really strong sequential arbitrage portfolios because the fulfillment of this property is straightforward. It is sufficient to check that the long position is cheaper than the short position but sequentially dominates. Moreover, it is also easy to check the lack a TSIR matching all bond prices unless prices fall in the percentage $£_{* *}$ for those bounds composing the short position. All the arbitrage strategies have been normalized so that the price of the short position can equal 10000,000 pesetas. ${ }^{5}$

A first group of examples refers to some strong sequential arbitrage opportunities characterized by surprising properties. In fact, they are extremely simple and generate too high values of $£_{* *}$. So, Table 3 shows several strategies only composed of two different $L T$ whose value at maturity is equal to 1000,000 pesetas. It is obvious that the tax effect or the lack of liquidity cannot explain the existence of these strategies because the involved $L T$ were traded almost everyday within the last quarter of 1998 and all the $L T$ have an analogous fiscal treatment. On the other hand, Table 4 presents two arbitrages involving another type of zero coupon bonds. Once again, illiquidity or taxes cannot explain these facts. Tables 3 and 4 only provide a small sample of these type of strategies that were available for a larger number of days.

Let us now focus on strong sequential arbitrage strategies involving coupon bonds. The first and second examples (Strategies 1 and 2) incorporate a coupon bond and several pure discount bonds, while Strategy 3 is more complex and involves several types of bonds in different position (see Tables 5,6 and 7 ).

Notice that above strategies have quite different form and some of them are non trivial, which shows the advantages provided by the applied methodology. The main conclusions of this study could not have been reached by testing the presence of

\footnotetext{
${ }^{5}$ The euro is the European currency since January 1, 1999 and, therefore, assets were still paid in pesetas in 1998. Besides, most of the maturities would take place after 1998, so the maturity value of many bonds might have been provided in euros. However, in order to use an unique currency, we will present the maturity value in pesetas as well.
} 
concrete sequential arbitrage portfolios.

Overall, the present analysis seems to be pioneer in testing the degree of sequential arbitrage in real bond markets and it seems to reveal the existence of available sequential arbitrage portfolios. This assertion is more obvious when markets incorporate significant financial innovations.

\section{Conclusions}

This paper has tested the level of sequential arbitrage in the Spanish bond market $M D A$ by drawing on the database elaborated by The Bank of Spain. Despite the vast empirical literature devoted to analyze the presence of arbitrage in stock and derivative markets, and the vast number of papers focusing on bond prices and the $T S I R$, it seems to be still scarce the degree of empirical evidence concerning the existence of sequential arbitrage in bond markets. In this sense the present study contributes to complete some possible gaps in the literature.

Empirical papers usually focus on well-known strategies when testing the existence of arbitrage. This technique cannot apply when dealing with bond markets and this is the reason why we followed recent developments that permit us to consider all the available arbitrage portfolios to choose the optimal one. In the present study the optimal strategy is selected by applying some minimax criteria that generate sequential arbitrage measures providing us with the minimum variation of prices leading to sequential arbitrage free models. The sequential arbitrage measures may be also understood as optimal relative sequential arbitrage earnings or incomes.

The first result of our study seems to draw an analogy between the strong sequential arbitrage and the second type sequential arbitrage. Although there are some theoretical differences between both concepts the empirical test seems to reveal that both approaches are quite close in practice.

The empirical results seems to indicate that the presence of sequential arbitrage cannot be rejected. Furthermore, the level of sequential arbitrage significantly raised in 1998, which suggests that the inexperience associated with important financial innovations may provoke inefficiencies in the market. These results are surprising by themselves and contrast with those provided by another tests of efficiency applied in the Spanish financial markets. Anyway, it is important to point out that analogous findings were obtained by a previous paper testing the level of arbitrage in the Spanish derivative market by means of global methodologies related to other arbitrage measures.

Our test only uses default free and option free bonds and, consequently, it is based on very weak hypotheses and the results seem to be quite robust. The lack of synchronization among prices and a non-homogeneous fiscal treatment for all the available bonds might slightly modify some results but the level of sequential arbitrage seems to be large enough to overcome these imperfections. 
Our findings may be useful to traders, managers and researchers because practical procedures to detect the presence of sequential arbitrage have been provided. Moreover, we have computed and analyzed many real sequential arbitrage strategies that were available in the market. Finally, as pointed out by previous papers, the arbitrage measurement may also be interesting when dealing with arbitrage free markets. In such a case the methodology here presented may be extended so that it can apply when pricing new bonds and composing optimal portfolios.

\section{REFERENCES}

[1] Ait-Sahalia, Y. and A.W. Lo, 1998, "Non-parametric estimation of state-price densities implicit in financial asset prices." The Journal of Finance, 53, 2, 499554.

[2] Aniz, A.R. and E.Z. Prisman, 2000, "After-tax term structures of real interest rates: Inferences from the U.K. linked and non-linked gilt markets." Journal of Banking and Finance, 24, 9, 1433-1455.

[3] Balbás, A., A. Ibáñez and S. López, 2001, "Dispersion measures as risk immunization measures." Journal of Banking and Finance, (forthcoming).

[4] Balbás, A., I.R. Longarela and A. Pardo, 2000, "Integration and arbitrage in the Spanish financial markets: an empirical approach." The Journal of Futures Markets, 20, 4, 321-344.

[5] Balbás, A. and S. López, 2000, "Sequential arbitrage measurement and envelopes for the TSIR." University Carlos III, Working Paper 00-53 (13).

[6] Balbás, A. and M.J. Muñoz, 1998, "Measuring the degree of fulfillment of the law of one price. Applications to financial markets integration." Investigaciones Económicas, 22, 2, 19-44.

[7] Bowden, R.J., 1997, "Generalizing interest rates duration with directional derivatives: Direction $X$ and applications." Management Science, 43, 5, 586-595.

[8] Chen, Z. and P.J. Knez, 1995, "Measurement of market integration and arbitrage." Review of Financial Studies 8, 2, 545-560.

[9] Elton, E.J., M.J. Gruber and R. Michaely, 1990, "The term structure of spot rates and immunization." The Journal of Finance, 65, 2, 629-642.

[10] Grinblatt, M. and F.A. Longstaff, 2000, "Financial innovation and the role of derivative securities: An empirical analysis of the U.S. treasury's strips program." The Journal of Finance (forthcoming). 
[11] Hansen, L.P. and R. Jagannathan, 1997, "Assessing specification errors in stochastic discount factor models." The Journal of Finance 52, 2, 567-590.

[12] Harris, F.H., T.H. McInish, G.L. Shoesmith, and R.A. Wood, 1995, "Cointegration, error correction, and price discovery on informatically linked security markets." Journal of Financial and Quantitative Analysis 30, 563-579.

[13] Holden, C., 1995, "Index arbitrage as cross-sectional market making." The Journal of Futures Markets 15, 4, 423-455.

[14] Ingersoll, J.,1989, "Theory of financial decision making." Totawa, NJ: Rowan Littlefield.

[15] Jaschke, S.R., 1998, "Arbitrage bounds for the term structure of interest rates." Finance and Stochastic 2, 29-40.

[16] Jouini, E. and H. Kallal, 1995, "Martingales and arbitrage in securities markets with transaction costs." Journal of Economic Theory 66, 178-197.

[17] Kamara, A. and T.W. Miller, 1995, "Daily and intradaily tests of European put-call parity." Journal of Financial and Quantitative Analysis 30, 4, 519-541.

[18] Kempf, A. and O. Korn, 1998, "Trading system and market integration." Journal of Financial Intermediation 7, 220-239.

[19] Lee, C.I. and I. Mathur, 1999, "Efficiency test in the Spanish futures markets." The Journal of Futures Markets 19, 59-77.

[20] Lee, J.H. and N. Nayar, 1993, " A Transactions data analysis of arbitrage between index options and index futures." The Journal of Futures Markets, 13, 8, 889-902.

[21] Liu, J. and F.A. Longstaff, 2000, "Losing money on arbitrages." Mimeo.

[22] Protopapadakis, A. and H.R. Stoll, 1983, "Spot and Futures Prices and the Law of One Price." The Journal of Finance 38: 1431-1455.

[23] Schleifer, A. and R.W. Vishny, 1997, "The limits of arbitrage." The Journal of Finance, 52, 35-55.

[24] Sternberg, J. S., 1994, "A reexamination of put-call parity on index futures." The Journal of Futures Markets 14, 79-101. 


\begin{tabular}{|c|c|c|c|c|c|}
\hline \multicolumn{6}{|l|}{ Table 1.} \\
\hline \multicolumn{6}{|l|}{ Year 1994} \\
\hline \multicolumn{6}{|c|}{$\begin{array}{l}245 \text { tested days } \\
56 \text { days reflect second type sequential arbitrage } \\
55 \text { days reflect strong sequential arbitrage }\end{array}$} \\
\hline "Value of $£_{*}$ & Number of days & $\%$ & "Value of $£_{* *}$ & days & $\%$ \\
\hline$\overline{£_{*}<0.001}$ & 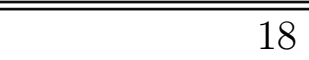 & 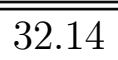 & $£_{* *}<0.001$ & 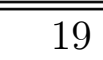 & 34.54 \\
\hline $0.001 \leq £_{*}<0.0025$ & 12 & 21.42 & $0.001 \leq £_{* *}<0.0025$ & 12 & 21.81 \\
\hline $0.0025 \leq \tilde{£}_{*}<0.005$ & 3 & 5.35 & $0.0025 \leq £_{* *}<0.005$ & 3 & 5.45 \\
\hline $0.005 \leq \tilde{£}_{*}<0.1$ & 9 & 16.07 & $0.005 \leq £_{* *}<0.1$ & 9 & 16.36 \\
\hline $0.01 \leq \tilde{£}_{*}<0.02$ & 8 & 14.28 & $0.01 \leq £_{* *}<0.02$ & 7 & 12.72 \\
\hline $0.02 \leq \tilde{£}_{*}<0.05$ & 6 & 10.71 & $0.02 \leq £_{* *}<0.05$ & 5 & 9.09 \\
\hline
\end{tabular}

\begin{tabular}{|c|c|c|c|c|c|}
\hline \multicolumn{6}{|l|}{ Table 2.} \\
\hline \multicolumn{6}{|l|}{ Year 1998} \\
\hline \multicolumn{6}{|c|}{$\begin{array}{l}246 \text { tested days } \\
231 \text { days reflect second type sequential arbitrage } \\
229 \text { days reflect strong sequential arbitrage }\end{array}$} \\
\hline "Value of $\tilde{£}_{*}$ & Number of days & $\%$ & "Value of $£_{* *}$ & days & $\%$ \\
\hline$\tilde{£}_{*}<0.001$ & 68 & 29.26 & $£_{* *}<0.001$ & 67 & 29.44 \\
\hline $0.001 \leq £_{*}<0.0025$ & 54 & 23.58 & $0.001 \leq £_{* *}<0.0025$ & 54 & 23.38 \\
\hline $0.0025 \leq £_{*}<0.005$ & 62 & 27.07 & $0.0025 \leq £_{* *}<0.005$ & 62 & 26.84 \\
\hline $0.005 \leq £_{*}<0.01$ & 17 & 6.99 & $0.005 \leq £_{* *}<0.01$ & 16 & 7.36 \\
\hline $0.01 \leq £_{*}<0.02$ & 6 & 2.62 & $0.01 \leq £_{* *}<0.02$ & 6 & 2.60 \\
\hline $0.02 \leq £_{*}<0.05$ & 24 & 10.48 & $0.02 \leq £_{* *}<0.05$ & 24 & 10.39 \\
\hline
\end{tabular}




\begin{tabular}{|c|c|c|c|c|c|}
\hline \multicolumn{6}{|c|}{ "Table 3. Arbitrage strategies involving "LT" } \\
\hline \multicolumn{6}{|c|}{ Year 1998} \\
\hline \multicolumn{6}{|c|}{$\begin{array}{l}\text { Column } 1 \text { indicates the date when the arbitrage occurred } \\
\text { Columns } 2,3,4 \text { and } 5 \text { refer to those bonds composing the strategy } \\
\text { Column } 6 \text { indicates } £_{* *} \text { in basic points }\end{array}$} \\
\hline Date & "Bond maturity & Value at maturity & Bond price & 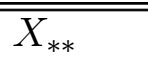 & $\overline{£_{* *}}$ \\
\hline \multirow[t]{2}{*}{ November 25} & "January 1, 1999 & 1000,000 & (962,980 & 10.099 & 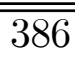 \\
\hline & March 18, 1999 & 1000,000 & 990,170 & -10.099 & \\
\hline \multirow[t]{2}{*}{ November 27} & January 4, 1999 & 1000,000 & 952,790 & 10.035 & 438 \\
\hline & January 8, 1999 & 1000,000 & 996,450 & -10.035 & \\
\hline \multirow[t]{2}{*}{ December 16} & January 8, 1999 & 1000,000 & 998,370 & -10.016 & 111 \\
\hline & January 4, 1999 & 1000,000 & 987,250 & 10.016 & \\
\hline \multirow[t]{2}{*}{ December 22} & January 4, 1999 & 1000,000 & 957,130 & 10.010 & 418 \\
\hline & January 8, 1999 & 1000,000 & 998,910 & -10.010 & \\
\hline
\end{tabular}

\begin{tabular}{|c|c|c|c|c|c|}
\hline \multicolumn{6}{|c|}{ Table 4. Arbitrage strategies involving strips } \\
\hline \multicolumn{6}{|c|}{ Year 1998} \\
\hline \multicolumn{6}{|c|}{$\begin{array}{l}\text { Column } 1 \text { indicates the date when the arbitrage occurred } \\
\text { Columns } 1,2,34 \text { and } 5 \text { refer to those bonds composing the strategy } \\
\text { Column } 6 \text { indicates } £_{* *} \text { in basic points }\end{array}$} \\
\hline Date & Bond maturity & Value at maturity & Bond price & 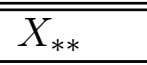 & $\sum_{* *}$ \\
\hline 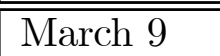 & & & & & "61 \\
\hline Small strip & January 31,2013 & 1000 & 440.8 & 22547 & \\
\hline Large strip & January 31,2013 & 10000,000 & 4435,100 & -2.2547 & \\
\hline April 4 & & & & & 29 \\
\hline Large strip & January 31,2013 & 10000,000 & 4539000 & -2.2031 & \\
\hline Small strip & January 31,2013 & 1000 & 452.6 & 22031 & \\
\hline
\end{tabular}




\begin{tabular}{|c|c|c|c|c|c|}
\hline \multicolumn{6}{|c|}{ February 5, 1998} \\
\hline \multicolumn{6}{|c|}{$\begin{array}{l}\text { Arbitrage with pure discount bonds and one coupon bond } \\
\text { The coupon is annual and equals } 1130 \\
\text { The strategy incorporates "LT" and strips }\end{array}$} \\
\hline$\overline{\overline{T y p e} \text { of bond }}$ & Bond maturity & Value at maturity & Bond price & $X_{* *}$ & $£_{* *}$ \\
\hline$\overline{\text { Coupon bond }}$ & 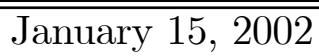 & 10000+last coupon & $\begin{array}{l}12396.11 \\
\end{array}$ & 802.7757 & 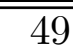 \\
\hline LT & January 22,1999 & 1000,000 & 961310 & -0.9071 & \\
\hline Small strip & January 31,2000 & 1000 & 921.39 & $-907,13$ & \\
\hline Small strip & January 31,2001 & 1000 & 879.88 & $\begin{array}{l}-907,13 \\
\end{array}$ & \\
\hline Small strip & January 31,2002 & 1000 & 838.73 & $\begin{array}{l}-8934,9 \\
\end{array}$ & \\
\hline
\end{tabular}

\begin{tabular}{|c|c|c|c|c|c|}
\hline \multicolumn{6}{|c|}{ Table 6. Strategy 2} \\
\hline \multicolumn{6}{|c|}{ March 26, 1998} \\
\hline \multicolumn{6}{|c|}{$\begin{array}{l}\text { Arbitrage with pure discount bonds and one coupon bond } \\
\text { The coupon is annual and equals } 1130 \\
\text { All the zero coupon bonds are strips }\end{array}$} \\
\hline$\overline{\text { Type of bond }}$ & Bond maturity & Value at maturity & Bond price & $X_{* *}$ & $£_{* *}$ \\
\hline Coupon bond & J January 15,2002 & 10000+last coupon & $\begin{array}{l}12555.21 \\
\end{array}$ & 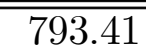 & 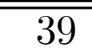 \\
\hline Small strip & January 31,1999 & 1000 & 967.19 & -897 & \\
\hline Small strip & January 31,2000 & 1000 & 929.97 & -897 & \\
\hline Small strip & January 31,2001 & 1000 & 888.09 & -897 & \\
\hline Small strip & January 31,2002 & 1000 & 849.64 & -8830.7 & \\
\hline
\end{tabular}

\begin{tabular}{|c|c|c|c|c|c|}
\hline \multicolumn{6}{|c|}{ Table 7. Strategy 3} \\
\hline \multicolumn{6}{|c|}{ May 4, 1998} \\
\hline \multicolumn{6}{|c|}{$\begin{array}{l}\text { All the involved coupons are annual } \\
£_{* *}=82 \text { basic points } \\
\text { The strategy incorporates several coupon and pure discount bonds }\end{array}$} \\
\hline Type of bond & "Bond maturity & $\begin{array}{l}\text { Value at maturity } \\
\end{array}$ & $\begin{array}{l}\text { Coupon } \\
\end{array}$ & $\begin{array}{l}\text { Bond price } \\
\end{array}$ & $X_{* *}$ \\
\hline 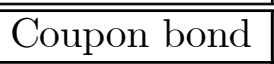 & $\begin{array}{l}\text { January } 31,2006 \\
\end{array}$ & 10000+last coupon & $\begin{array}{l}1015 \\
\end{array}$ & $\begin{array}{l}13408.92 \\
\end{array}$ & $\begin{array}{l}739.655 \\
\end{array}$ \\
\hline Coupon bond & January 31,2001 & $10000+$ last coupon & 500 & 10269.2 & -71.5 \\
\hline Large strip & January 31,2003 & 10000,000 & 0 & 8032800 & -0.075075 \\
\hline Small strip & January 31,1999 & 1000 & 0 & 970.17 & -715 \\
\hline Small strip & January 31,2000 & 1000 & 0 & 931.24 & -715 \\
\hline
\end{tabular}

